\title{
TVORBA RIJEČI U JEDNOM ZANIMLJIVOM KORPUSU
}

U prilogu se analiziraju i primjerima ilustriraju postupci tvorbe riječi u knjizi Kaleidoskop povjesničarke umjetnosti i književnice Željke Čorak, u usporedbi s nekim njezinim kasnijim djelima. Mnoštvo zanimljivih tzv. individualnih ili ad hoc tvorevina dokazuje $s$ jedne strane kreativnost i bogatstvo autoričina jezika, $s$ druge strane vitalnost i plodnost dotičnih tvorbenih postupaka u suvremenom hrvatskom jeziku.

1. Među djelima suvremene hrvatske nefikcionalne književnosti posebno mjesto pripada tekstovima istaknute ličnosti suvremene hrvatske kulture, povjesničarke umjetnosti, književnice i publicistkinje Željke Čorak, prisutne na tim poljima preko trideset godina. Virtuoznost njezina jezika i stila dobro je poznata našoj kulturnoj javnosti, a jedan je od elemenata u tome i tvorba riječi, važna komponenta bogaćenja leksika (uz posuđenice i semantičke promjene). Tvorbeni postupci u jeziku naše autorice ilustriraju njezinu inventivnost $\mathrm{i}$ kreativnost kako u uporabi postojecih tako i u stvaranju novih izražajnih mogućnosti. Budući da, međutim, u najnovijem i najboljem prikazu tvorbe riječi u hrvatskom jeziku (Babić 1986; odsada dalje: Babić) nije izričito navedeno jesu li djela Željke Čorak - kao i tolika druga - uzeta u obzir, ${ }^{1}$ držimo da će biti zanimljivo i korisno proučiti one primjere tvorbe koje bi svakako, s punim imenom, valjalo uvrstiti u materijal za taj studij. Većina je glavnih autoričinih djela objavljena doduše nakon Babićeve knjige (v. bibliografiju), ali jedna je njezina knjiga, Kaleidoskop, izišla 1970. godine, a druga 1981. godine. Kako u svim autoričinim tekstovima nalazimo impresivan niz tvorbeno zanimljivih primjera, uključit ćemo i njih u prilog što slijedi, koncentrirajući se ipak na Kaleidoskop, koji će nam biti temeljni korpus. Vrijedno je naime pokazati da već to mladenačko djelo Željke Čorak, zbirka kritika, osvrta i eseja objavljenih od 1965. do 1970. godine, sadrži sve ono bogatstvo jezika koje karakterizira i njezin kasniji rad. A budući da je od najranijega teksta u Kaleidoskopu, eseja o Le Corbusieru iz g. 1965, do posljednje ovdje upotrijebljene knjige, Zagreb, pisani prostor (1994) prošlo tridesetak godina, bit će zanimljivo pratiti i eventualni razvoj autoričinih tvorbenih postupaka u tom periodu. U našem izboru primjerâ citirat cemo svaki od njih u kontekstu potrebnom za razumijevanje semantičke, stilističke, pragmalingvističke i tekstovne komponente, a gdje smatramo potrebnim, dodat ćemo i vlastiti komentar. Ovim prilogom želimo s jedne strane

1 Na 8. strani govori se o izvorima, ali se ne navode oni autori koji nisu posebno citirani nego samo ekscerpirani, tako da se ti autori mogu utvrditi samo prepoznavanjem citatâ. 
doprinijeti prikazu tvorbe riječi u navedenoj Babićevoj monografiji, a s druge strane osvijetliti jednu, i to ne najmanje važnu, stranu jezika i stila naše poznate autorice.

2. Što se tiče teoretsko-metodoloških osnova, slažemo se uglavnom sa S. Babićem, koji u $§ 70$ svoje knjige razlikuje izvođenje (derivaciju) i slaganje (kompoziciju) kao dva temeljna načina tvorbe riječi. Ipak mislimo da se tvorba prefiksima može izdvojiti kao treći temeljni postupak (obrazloženje bi nas odvelo daleko izvan dopuštenih dimenzija ovoga rada), a za ono što Babić ( $\$ 104-107)$ naziva prefiksalno-sufiksalnom tvorbom služimo se kraćim terminom parasintetička tvorba (rezultat su dakle parasintetici). Dok se u toj tvorbi radi o istodobnom dodavanju prefiksa i afiksa ${ }^{2}$ (npr. $o$ + moguć + iti $\rightarrow$ omogućiti; ne postoji ni *omoguć ni *mogućiti), u onome što Babić definira kao složeno-sufiksalnu tvorbu ( $\$ 93-94)$ mi vidimo također izvođenje ali od prethodno tvorenih osnova, koje mogu biti prijedložne sintagme (preko + Save $\rightarrow$ prekosavski) ili složenice (bijeli + svijet $\rightarrow$ bjelosvjetski; usp. Anić 1998 /odsada: Anić/, str. 1409 , točka 19). U takvim tvorevinama ne može se govoriti o is to dobnom dodavanju tvorbenih elemenata ispred i iza osnove nego o dodavanju sufiksa kao posljednjega tvorbenog čina (v. za taj pojam Babic $\$ \$ 32,58,64$ i dr.). Isto je tako npr. u talijanskom crocerossina 'djelatnica Crvenog križa' izvedeno od Croce Rossa sufiksom -ina, a ne istodobnim dodavanjem Croce i -ina na osnovu Rossa ili sl.

Uz nabrojene tvorbene postupke postoje još dva. Prvi je izvođenje tzv. nultim sufiksom (Babić §§84-85, 1008-1113 i dr.), uglavnom u tvorbi imenica od glagolâ, tj. deverbalâ, kao plač $(\leftarrow$ plakati), posjet $(\leftarrow$ posjetiti) itd. Drugi je način tvorba tzv. prefiksoidima i sufiksoidima, tj. internacionalnim (latinskim ili grčkim elementima), koji su u određenom smislu na pola puta između prefiksâ i sufiksâ s jeđne, a posve samostalnih leksičkih elemenata (riječi) s druge strane. Dok prefiksi odn. sufiksi mogu stajati samo ispred odn. iza osnove, neki »-oidni« tvorbeni elementi mogući su u oba položaja, npr. fil-antrop prema ruso-fil. Ti elementi uglavnom nisu samostalne riječi, ali se mogu osamostaliti (npr. auto).

3. U ovom paragrafu, redom stranica u Kaleidoskopu, analiziramo primjere tvorbe riječi koje smatramo zanimljivima, navodeći prigodice usporedbe s kasnijim djelima Željke Čorak i podatke iz konzultiranih leksikografskih priručnika, a to su Anić, Benešić 1985-1990 (odsada dalje: Benešić) i, kao jedan od najboljih dvojezičnih rječnika, Deanović-Jernej 1993 (odsada: Deanović-Jernej). Gdje se rječnici ne citiraju, znači da dotične riječi u njima nema.

1) A ispod staklenastih opni nazre se nejasan lik, pretvorljiv u mnoštvo slika [...] (str. 12)

2 Afiks je širi pojam nego sufiks, pa obuhvaća ne samo tvorbu sufiksima (pjev-ač) nego i tvorbu gramatičkim morfemima (npr. sol-iti, gdje segment -iti nije sufiks nego gramatički morfem komutabilan s drugima u pojedinim paradigmama). 
Značenje pridjeva pretvorljiv jasno je: mogućnost onoga što kazuje osnova (Babić $\S \S 1602-1617,1648-1649)$. Anić i Deanović-Jernej navode pretvorljiv s. v. pretvoriv, a Benešić daje za pretvorljiv primjer iz V. Kaleba. Za isti tip pridjeva v. i primjer 8.

2) su-vremenost Mirka Račkog (str. 25)

Kako u Kaleidoskopu nema primjerâ pogrešnoga zadržavanja crtice unutar riječi, su-vremenost neće biti pogreška umjesto suvremenost nego svjesna grafija, koju možemo definirati kao re-motivaciju, jer u neposredno prethodnom odlomku stoji ovo:

2a) Neke faze Mirka Račkog, nezavisno i od nacionalno-sadržajnih poticaja $i$ od postignute likovne kvalitete, morat će se iznova odmjeriti sa stanovišta položaja u vremenu.

Grafija su-vremenost vjerojatno želi dakle istaknuti da ta riječ ne znači 'ono što supostoji danas s nama' nego 'ono što u svojem vremenu koincidira s nečim drugim' (usp. za suvremenost Anić s. v.), da se prema tome slike određuju u skladu s vremenom postanka. Zahvaljujući toj re-motivaciji ubrajamo i autoričino su-vremenost u tvorbu riječi.

3) Taj beskrajno promjenljiv [...] značenjem pregust prostor, taj svemir koji se [...] ukazuje u smionim kadrovima crteža na temu Dantea, to ludo oprostorenje puta kojim samo misao može proći, temelj je veličine Račkog [...] (loco ult. cit.)

Imenica oprostorenje izvedena je od parasintetičkoga glagola oprostoriti, koji se može parafrazirati kao 'pretvoriti u prostor', 'providjeti prostorom' ili sl. Babić tu tvorbu obrađuje u $\S \S 1922-1929$, no našega primjera nema, jer je to sigurno ad hoc tvorevina, što dokazuje da je taj tvorbeni postupak još plodan ${ }^{3}$ (usp. imenicu osedravanje u primjeru $21 \mathrm{i}$, kasnije, odragocjenjenje, u UFZ str. 197, koja je bez sumnje također individualna tvorevina).

4) sklonost prema sinteznoj i sugestivnoj moći naivnog i dječjeg crteža [...] (str. 33)

Pridjev sintezni, tvoren po modelu npr. kriza $\rightarrow$ krizni, dolazi i kasnije, u primjeru vrhunska ostvarenja [...] moraju biti i jesu sintezna (str. 103), zatim u navedenoj knjizi UFZ (str. 79 i 133), i u suvremenom dnevnom tisku (S. Križić Roban, Umjetnička topografija Hrvatske, Vjesnik 10. 9. 1997, str. 17; Živana Morić, Ostavka suprotiva Marulu, Vjesnik 23. 4. 1998, str. 25). Pridjev sintezni znači otprilike 'ono što ima karakter(istike) sinteze', pa se time razlikuje od pridjevâ sintetičan i sintetički, koji označavaju ono što je rezultat sinteze (najčešće u tehnološkom ili sličnom smislu, usp. Anić ss. vv.). Babić obrađuje tvorbu pridjevâ sufiksom -ni detaljno i na mnogo prostora (§§1409-1462), ali primjer sintezni nismo našli. Analogna je tvorevina gostoprimni

3 Kao dokaz navodimo primjer kontemplativno oprostorenje umjetničinih simbola, u napisu Sandre Križić Roban Otvaranje jajeta, Vjesnik 31. ožujka 1998, str. 18. Takve tvorevine spominje i Anić, među onima koje nisu uvrštene u njegov rječnik (str. 1439, točka 129). 
(UFZ, str. 95), koja se u svojem kontekstu razlikuje od običnijega gostoprimljiv (Deanović-Jernej s. v., Benešić s. v. s primjerom iz Ujevića).

5) mračne rupe nozdrva, očiju, usta rastvorena u posljednjem udahu davljenika. Razmreživanje života u podzemnu izjednačenost svega što sa zemlje silazi. (str. 36; o slikama Nives Kavurić-Kurtovic)

Imenica razmreživanje izvedena je od parasintetičkoga glagola razmreživati, koji ovdje ima značenje što ga Babić (\$1903) navodi kao prvo od četiri moguća značenja za prefiks raz-, tj. da se radnja vrši ili širi na različite strane, ali nisu isključena ni ostala (intenzifikacija, postignuce cilja, radnja u suprotnom smjeru; loco cit.). Analogno je stvoren primjer razravnoteženje [u inače simetričnoj kompoziciji] (UFZ, str. 78), također deverbal od glagola razravnotežiti, i to u četvrtom od Babicevih značenja (suprotnost od uravnotežiti, Anić s. v.; Deanović-Jernej uz glagol daju i imenicu uravnoteženje, ss. vv.). ${ }^{4}$

6) Sili teži nepodvrgnuti, u zajedničkoj plazmi embrioni čekaju izraštenje. (str. 37)

Imenica izraštenje (u opisu jedne slike) izvedena je iz glagola izrasti, koji je perfektivan. Babić ( $\S 474-475)$ naglašava plodnost te tvorbe od imperfektivnih glagola nasuprot ograničenjima od perfektivnih (nekoliko primjera za ove u $\S \S 480-482$ ), pa u takve u načelu rijetke tvorevine spada in naš primjer.

7) potrebno je pažljivo pratiti sve što sliku sačinjava: kompoziciju kadra, njenu zgusnutost ili raspršenost, usredištenost ili pomak prema rubovima [...] (str. 40)

I imenica usredištenost izvedenica je od parasintetičkoga glagola usredištiti, posve motiviranoga i semantički transparentnoga u značenju 'dovesti nešto u središte', koje je različito od običnijega usredotočiti 'koncentrirati pažnju ili sl. na nešto (što već jest) u središtu' (usp. Anić s. v.). Tu se dakle radi o lokalnom značenju, koje je jedno od četiri što ih navodi Babić (\$§1912-1914 i 1931): ulaženje, obuhvaćanje sa svih strana, krajnja zamorenost, postignuce cilja.

8) Kuduz se samom strukturom svoje grafike suprotstavlja potrošivosti, naglašeno antitetično [...] (str. 43-44)

To je motivirana izvedenica od pridjeva potrošiv, jednog od pridjeva koji izriču mogućnost vršenja radnje ako je glagol od kojega su izvedeni prijelazan, kao ovdje (potrošiv $\leftarrow$ potrošiti, prenosiv $\leftarrow$ prenositi, čitliji $\leftarrow$ čitati), a ako nije prijelazan, mogu značiti i sposobnost ili sklonost (plačljiv $\leftarrow$ plakati, razdražljiv $\leftarrow$ razdražiti (se) itd.); usp. Babić §§1608-1610. Antonim ovdje navedenoga pridjeva, tj. nepotrošiv,

4 U dokaz plodnosti takvih individualnih i zaista ad hoc tvorevina evo primjera: jednom smo u gradskom autobusu u Puli čuli kako mlada majka opominje kćerkicu da se drži za držač, jer: ako naglo zakoči, past ćeš $i$ razlijepit ceš se ko palačinka. Slika je izvanredna: malo dijete faktično pljusne »sa sve četiri širom « ( $\mathrm{raz}^{-}$), ne zna ustati pa izgleda kao da se zalijepilo za pod (uz to naravno plače i zove mamu). 
upotrijebila je Željka Čorak, kao lijepu metaforu, u opisu zanimljivosti i trajne vrijednosti starih časopisa (KR, str. 192), a istovrsne su i njezine tvorevine neobrazloživ (KR, str. 81), nezavršiv (ZK, str. 269), uništiv (KR, str. 94) (a ima i drugih). Posljednja tri pridjeva donosi i Anić (ss. vv.), dok Deanović-Jernej daju samo oblike potrošljiv i unišstljiv (ss. vv.). Usp. nepreskočiv, Vijnac 4. 6. 1998, str. 17.

9) [o demokratizaciji umjetnosti] pristupačnošću [...] formalnim pojednostavnjenjem [...] i tehničkom umnogostručivošću [...] (str. 45)

Od ta tri apstrakta (dva od pridjevâ, jedan od glagola) tvorbeno je najzanimljiviji posljednji. On je potpuno motiviran i semantički transparentan, a u tvorbenom je smislu rezultat čak četiriju tvorbenih činova:

$$
4\left(3\left(2\left(u+{ }_{1}(\text { mnogo }+s t r u k)_{1}+i t i\right)_{2}+i v\right)_{3}+o s t\right)_{4}
$$

Odnosno, u obliku »stabla

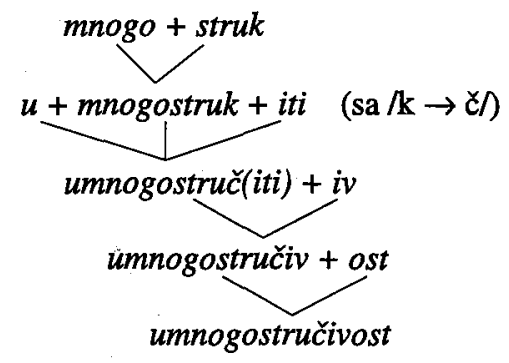

Analogna je imenica umnoživost (str. 51) od pridjeva umnoživ, koji DeanovićJernej daju na prvom mjestu, a umnožljiv na drugom.

10) slikarstvo Kalajićeva tipa dovodi u pitanje jednoobličnost njegova unutrašnjeg postojanja. (str. 46)

I jednoobličnost ima značajke ad hoc tvorevine, tj. motiviranost i semantičku transparentnost, a osnova može biti kako jednooblik (po modelu jednolik $\rightarrow$ jednoličnost; Anić ss. vv.), tako i jednoličan (Anić s. v.).

11) ne dopustiti strojevnim zakonitostima [...] da naizmjeničnim identifikacijama - za čovjekolikim strojem slijedi strojoliki čovjek - priguše svijest o čovjekovoj nezamjenljivosti. (str. 51)

Pridjev strojolik, u hijazmu (»zrcalnom kontrastu «) $)^{5}$ sa čovjekolik, izgleda također kao ad hoc tvorevina (po jasnom i posve motiviranom modelu), jer ga nijedan od naših izvora ne donosi. V. za hijazam i primjer 27.

5 Takvi su hijazmi, u raznim varijantama, čest stilem u jeziku Željke Čorak, pa evo izbora primjera: čovjek je trenutačnost trajnog. Covjek je trajnost trenutačnog. (str. 6); u njega [Matissea] se može govoriti o »dubini površine«; u Postružnika o »površini dubine« (str. 31); Zaštita spomenika je u neku ruku urbanizam unatrag, kao što bi urbanizam morao biti zaštita unaprijed. (str. 99); stvoriti iz slobode svoju nužnost, ili iz nužnosti svoju slobodu. (str. 103); I tako se iz privremenog koje sadrži privid zakona, sastavlja vrijeme koje otkriva zakon privida. (str. 139); Doživljaj ne počinje iz 
12) kao da uistinu tek razbroj može otkriti onaj poticaj za mišljenje koji predstavlja stvarnu vrijednost ovog zbroja. (str. 52)

Imenica razbroj, antonim od zbroj, može se opisati bilo kao tvorevina zamjenom prefiksa $s$ - (sa $/ \mathrm{s} \rightarrow \mathrm{z} /$ ) prefiksom raz- sa značenjem radnje u suprotnom smjeru, bilo kao deverbalna izvedenica od razbrojiti (koji imaju Benešić i Deanović-Jernej) ali to po značenju manje odgovara.

13) [komentar jedne fotografije] stari [je] istočnjak, miru veoma odan [...] znajući da kupca čeka uzalud, osigurao cjelodnevni drijemež svojoj misli a nepokret svome tijelu [...] (str. 57)

Imenica nepokret, koju ne bilježi nijedan naš izvor, i opet jednom izgleda kao ad hoc tvorevina, i to bilo negacijom imenice pokret (prema mir $\rightarrow$ nemir, red $\rightarrow$ nered itd.), bilo izvođenjem iz nepokretan nultim sufiksom (po modelu nepovrat $\leftarrow$ nepovratan). U OPGM, str. 19 , stoji sintagma $u$ poziciji nepokreta. ${ }^{6}$

14) Osamljenjem motiva od sklopa u kojem se nalazi [...] autor pojačava njegovu [...] sadržajnost [...] (str. 58)

Imenica osamljenje nije sinonim od osamljenost, jer je deverbal pa označava radnju, dok osamljenost znači stanje koje je rezultat procesa osamljenja. Deanović-Jernej daju obje riječi, u djelomičnoj sinonimiji.

15) [o fotografijama] one iznova sastavljaju [...] svijet koji promatramo i u koji su te bilješke pogleda mnogosmjerno ulazile. (str. 60)

Prilog mnogosmjerno izveden je dakako od pridjeva mnogosmjeran, koji se uklapa u niz mnogobojan, mnogobrojan, mnogoglasan, mnogojezičan, mnogosložan, mnogovrstan itd. (Deanović-Jernej ss. vv.) odnosno mnogobrojan, mnogoljudan, mnogoslojan (Anić ss. vv.). Sve su to izvedenice sufiksom -(a)n od složenih osnova pa se time razlikuju od semantički istovrsnih tvorevina kao mnogostran, mnogostruk itd., u kojima imamo nulti sufiks.

16) To što mi zapostavljamo neka područja, ne znači da ona prestaju postojati i da se istina svijeta sutra neće ukazati drukčijom od one kojoj smo privrženi (ili nas privrgavaju) danas. (str. 62)

staroga prema novom. Doživljaj počinje iz novoga prema starom. (ZPP, str. 159); Bosna [...] će u novijoj povijesti biti zabilježena po srazu slobodnog pada i pada slobode. (OPGM, str. 42); [jer mi se] pravim pitanjem ne čini sloboda kulture, nego kultura slobode. (ib., str. 46; v. i str. 47 i 50); $T i$ nisi potonula katedrala, ali si svakako katedrala potonuloga grada. (ZK, str. 261). Poseban je ovaj primjer iz Krhotina (str. 181): jedan kovač u Prezidu, koji je autoričinu djedu pravio kola, istaknuo je jednom na kući obavijest da nije kod kuće; djed je šaljivo dopisao Pije, na što se majstor naljutio: jer je šala odgovarala istini. Ali je kola napravio jednako čvrsta i lijepa, budući da se tada istina rado klanjala šali.

6 Genitiv nepokreta primjer je onoga što nazivamo upotpunjenjem paradigme (v. i primj. 26). Tako je potpisani autor mislio da riječ nepovrat dolazi samo u akuzativu s prijedlogom $u$ (kako i stoji $u$ Aniću, Benešiću i Deanović-Jerneju), dok nije naišao na Batušićev podnaslov Slike iz nepovrata (Laterna magica, PSHK, Zagreb 1963, str. 56). 
Glagol privrgavati semantički je u vezi s pridjevom privržen, a što se tiče tvorbe, on je rezultat imperfektivizacije (o čemu v. Babić \$\$1764-1836) »među-etape« privrgnuti, po modelu izvrgnuti - izvrgavati, razvrgnuti - razvrgavati i sl. (v. Anic ss. vv.). U o vom kontekstu on je svakako bar djelomično, individualna tvorevina. Za imperfektivizaciju ima u jeziku Željke Čorak i drugih primjera, npr. preduhitrivati (KR, str. 30), nastanjivati (ib., str. 99) (koje Anić ima), ugrebavanje ( $\leftarrow$ ugrebavati) (ib., str. 101), preslagivati (ib., str. 104) (ova posljednja dva Anić nema) itd.

17) Tako se lecnemo ili pribojimo ako se samostanske ćelije pretvaraju $u$ hotelske sobe [...] (str. 78)

Oblik pribojimo (se) pretpostavlja infinitiv *pribojati se, a to je posve sigurno individualna i ad hoc tvorevina. Taj je glagol perfektivan, kao i lecnuti se, s kojim je u disjunktivnom paru. Originalnost je upravo u kombinaciji perfektivnoga aspekta sa značenjem osjećaja ublaženoga, umanjenoga straha kao očito trajnoga stanja (usp. Anić s. v. pribojavati se). Babić našega glagola naravno nema ni u paragrafima o perfektivizaciji $(\$ \$ 1759-1763)$ ni u onima o prefiksu pri( $\$ 1895-1896)$, a ne nalazimo ga ni u jednom od konzultiranih rječnika.

18) takve galerije i muzeji ponekad su samo [...] spremnice [...] ad hoc sabranih i neucjelovljenih izložaka [...] (ista str.)

Osnova participa ucjelovljen nije naravno imenica cjelov ( $\mathrm{s}$ kojom je tek $\mathrm{u}$ dalekom srodstvu, v. Skok ERHSJ s. v. cio) nego glagol ucjeloviti, parasintetička izvedenica od pridjeva cjelovit (uz odbacivanje sufiksa -vit, o kome v. Babić $\$ \$ 1642-1647$ ), a negativni je prefiks ne- posljednji tvorbeni čin.

19) Nepodesni depoi i nedostatak suvremene tehničke opreme čine od tih ustanova često propadališta, a ne spremišta dragocjenih djela. (str. 81)

Kako tvorbena tako i semantička strana posve su jasne, pa je motivacija potpuna, naročito u kontrastu sa spremišta.

20) današnje svevrijedno mjerilo devizne zarade, varavo primamljive posljedice turističke eksplozije [...] (str. 91)

Pridjev svevrijedan, koji ne donosi nijedan od naših izvora, složenica je (po modelu svenazočan, sveopći itd.; Anić, ss. vv.), ovdje aktualizirana u pomalo ironičkom značenju (radi se o očuvanju Plitvica), koje se dodiruje sa pridjevom svemoguć ili svemoćan (»svemoguće« devize, nenadmašive po vrijednosti).

21) proces osedravanja, osnovni fenomen Plitvickih jezera (loco cit.)

Od imenica sedra stvoren je parasintetički glagol osedravati, koji označava polagani prirodni proces (tu dakle perfektivni pandan ne bi bio moguć). Nema ga ni Babić ( $\$ 1922-1929)$ ni naši rječnici.

22) čovjek svojom mjerom teško može obuhvatiti sav raspon ovakve gigantizirane skulpture-arhitekture [...] (str. 119)

Ovdje se komentira zaista naivna zamisao arhitekta Nicolasa Schöffera o neboderima do $1500 \mathrm{~m}$. visine i kilometarskim stambenim blokovima, pa je glagol 
gigantizirati posve opravdan i kao značenje i kao tvorevina. Isti se glagol javlja u autoričinim tekstovima još dva puta: u Kaleidoskopu, na str. 128, nalazimo gerundij gigantizirajući, a particip stoji u ZPP, gdje na 109. strani Željka Čorak duhovito komentira izgradnju Zagreba (konkretno Trnja) u obliku izoliranih objekata:

22a)Nikada rasut i diskontinuiran skup objekata nije uspio postati grad. Po svojoj naravi on je gigantizirano selo bez zemlje.

Po Babiću (§§1723-1724) tvorba glagola na -izirati plodna je u suvremenom jeziku, i zaista može se navesti još niz tvorevina koje se javijaju tako reći svakodnevno. Iz autoričinih se djela mogu citirati npr. minijaturizacija (KR, str. 97), estetiziran (ib., str. 116), i ekspresivizirati (ZPP, str. 168; o portalu zagrebačke katedrale), a iz svakodnevnog jezika, terminologije i žargona navodimo iz Anica ourizirati (ourizacija nema), iz suvremene političke terminologije finlandizacija (ni u jednom rječniku), a u Vjesniku od 9. travnja 1998, na 15. strani, u jednom satiričnom napisu o zapadnjačkom utjecaju spominju se kokakolaizacija, mekdonaldizacija i plejbojizacija. Boljega dokaza plodnosti te tvorbe valjda uopće nema!

23) takva [je] staklena opna katkad uokružena uskim zidanim okvirom [...] (str. 124)

Glagol uokružiti, bar u ovom kontekstu, nema isto značenje kao običniji glagol zaokružiti: dok ovaj drugi znači 'dati nečemu okrugao, potpun oblik', naš glagol (u tekstu o tlocrtu crkve) znači 'staviti nešto u krug okružen ili omeđen čime'. Među glagolima tvorenim prefiksom $u$ - Babić ( $\$ 1912-1914$ i 1931) nema glagola uokružiti.

24) Promajna [...] za koju se čini da se jedino ovako blokovita $i$ sabijena može održati na svom komadiću tla. (str. 128)

Ovdje se makedonsko selo Galičnik, rastreseno na kosini brijega, uspoređuje s dalmatinskom Promajnom, koja je »zgusnuta na uzak pojas obale i zatvorena golemim planinskim masivom « (loco cit.). Pridjev blokovit znači 'nalik na blok' ili 'sastavljen od blokova', dakle sličnost ili sastav (Babić §§1643-1644), a nalazimo ga još dva puta: u UFZ, str. 171, i u ZPP, str. 97 (u ovom drugom slučaju može značiti samo 'nalik na blok', jer se radi o opisu jedne vile). Za usporedbu možemo navesti i pridjev šokovit (ZPP, str. 69; u opisu krematorija), koji prema kontekstu znači 'ono što ima karakter šoka' ili je 'rezultat šoka' ili sl., za razliku od običnijega šokantan (npr. ZPP, str. 167, i ZK, str. 296) 'ono što šokira' (Anić s. v.). Obje ovdje navedene izvedenice na -ovit vjerojatno su individualne ad hoc tvorbe: naši ih izvori ne bilježe.

25) pred perspektivom dosadno ujednoličenog svijeta, ne bi li neke krajeve [...] trebalo [...] očuvati u njihovu [...] stoljetnom skladu? (str. 129)

Particip ujednoličen pretpostavlja infinitiv ujednoličiti, a to je parasintetička tvorevina od osnove jednolik (sa $/ \mathrm{k} \rightarrow$ č/) ili jednoličan s odbacivanjem sufiksa -an kao u obilan $\rightarrow$ obilovati i sl. Zgodno je navesti i antonim uraznoličen (UFZ, str. 102) i izvedenicu uraznoličenje (ib., str. 148). Kao model u ovoj tvorbi mogli su poslužiti glagoli uobličiti, uravnotežiti i sl. (Anic, ss. vv.). 
26) Taj svijet koji još uvijek posjedujemo nalazi se na izmaku, no u izmak ne bi trebalo da povuče i tolika svoja iskustva korisna našem vremenu. (loco cit.)

Imenica izmak (Anić s. v., Deanović-Jernej s. v., Babić §1085) uobičajena je u lokativu s prijedlogom na, pa su i primjeri u dvama spomenutim rječnicima takvi, dok npr. Benešić donosi i nekoliko primjera u genitivu (nema odn. nije bilo izmaka). Autoričina sintagma $u$ izmak, s prijedlogom $u$ i akuzativom smjera, primjer je upotpunjenja paradigme, kao i genitivi nepokreta i nepovrata citirani u bilješci 6 .

27) svjetiljka je [...] metafora života koji izgarajući uzrasta i uzrastajući izgara [...] (str. 135)

Glagol uzrastati, u ovoj efektnoj metafori (koja je također primjer »zrcalnoga kontrasta«, v. primj. 11), rezultat je imperfektivizacije uobičajenoga uzrasti, opravdane upravo paralelizmom polaganoga izgaranja svjetiljke - i života. Model su glagoli dorastati, izrastati, narastati, urastati i sl. (Anić ss. vv., Babić §1773), dok uzrastati u izvorima nema.

4. Prethodno izlaganje, koje se može dopuniti i drugim primjerima, ${ }^{7}$ pokazuje da su u jeziku Željke Čorak zastupljeni svi tvorbeni postupci:

- izvođenje od jednostavnih osnova: blokovit, gigantizirati, sintezni, šokovit itd.;

- izvođenje od složenica: mnogosmjeran;

- izvođenje od glagola s prefiksima: podsjećaj, potrošiv, pretvorljiv;

- izvođenje od parasintetika: oprostorenje, usredištenost i drugi;

- izvođenje nultim sufiksom: podsjet;

- tvorba prefiksima: privrgavati, pribojati se, razbroj;

- slaganje: strojolik;

- parasintetičke tvorevine: svi glagoli u osnovi izvedenicâ kao oprostorenje i sl.

Posebno se mogu istaknuti komplementarni postupci imperfektivizacije (privrgavati) i perfektivizacije (pribojati se), koji su bez sumnje najindividualnije autoričine tvorbene kreacije u korpusu, kao i remotivacija u su-vremenost. A kao osobito zanimljiv primjer ističemo izvedenicu umnogostručivost, analiziranu $\mathrm{u}$ primjeru br. 9.

7 Npr.: 1) deverbali zamišljaj (KR, str. 40) i podsjećaj (ib., str. 97); 2) deverbal nultim sufiksom podsjet (KR, str. 202), negativno konotiran pridjevom gorak (upropašteni nakit, draga uspomena), dok je podsjećaj pozitivno obilježen (veselje u obilaženju sajmova); 3) parasintetik prevapniti (KR, str. 198: o preinakama u staroj obiteljskoj kući; subjekt je vrijeme); 4) izvedenica dvokomponentnost ( $\mathrm{KR}$, str. 74: opis boje na starom vrčiću) od pridjeva dvokomponentan ( $\rightarrow$ dvije komponente); usp. dvokuća, izraz za dvije bliske i funkcionalno vezane kuće (ZPP, str. 124 i 125; UFZ, str. 212 i bilj. 198); 5) particip turistificiran (inf. turistificirati), o prostoru pred Mimarom (ZPP, str. 83) itd.; a mogao bi se navesti i niz drugih primjera. 
Sve su ovdje analizirane tvorevine $s$ jedne strane dokaz plodnosti tvorbe riječi u suvremenom hrvatskom jeziku, a s druge strane one su ilustracija jezičnoga i stilskoga majstorstva Željke Čorak (da sve njezine tvorevine imaju izrazite stilske vrijednosti, vjerojatno nije uopće potrebno napose dokazivati).

\section{Navedena djela}

A. Korpus - djela Željke Čorak:

Kaleidoskop, Zagreb 1970. (polazni korpus; citira se bez kratice).

UFZ: U funkciji znaka. Drago Ibler $i$ hrvatska arhitektura između dva rata, Zagreb 1981.

ZK: Zagrebačka katedrala (u suautorstvu s Anom Deanović, Zagreb 1988.

KR: Krhotine. Prilog poznavanju hrvatske provincije u devetnaestom stoljeću, Zagreb 1991.

OPGM: Oproštajno pismo gospodinu Mitterrandu, Zagreb 1993.

ZPP: Zagreb, pisani prostor, Zagreb 1994.

B. Ostali naslovi:

Anić 1998: V. Anić, Rječnik hrvatskog jezika, Zagreb.

Babić 1986: S. Babić, Tvorba riječi u hrvatskom književnom jeziku, Zagreb.

Benešić 1985-1990: J. Benešic, Rječnik hrvatskoga književnoga jezika od Preporoda do Ivana Gorana Kovačića, 1-12, Zagreb.

Deanović-Jernej 1993: M. Deanović - J. Jernej, Hrvatsko-talijanski rječnik, Zagreb.

Skok ERHSJ: P. Skok, Etimologijski rječnik hrvatskoga ili srpskoga jezika I-IV, Zagreb 1971-1974.

Abstract

THE TYPES OF WORD FORMATION IN THE WORKS OF ŽELJKA ČORAK

The article analyzes types of word formation (derivation, composition, prefixation, parasynthetics etc.) in the works of Željka Črak, an outstanding contemporary Croatian writer. In her texts (from 1970 to 1994), besides the common examples many so-called ad hoc or individual formations are attested that show both linguistic (and stylistic) creativity of the author and vitality of word formation in present-day standard Croatian. 